\title{
The effect of orofacial complete Freund's adjuvant treatment on the expression of migraine-related molecules
}

\author{
Tamás Körtési ${ }^{1}$, Bernadett Tuka², Aliz Nyári, László Vécsei²,3 and János Tajti
}

\begin{abstract}
Background: Migraine is a neurovascular primary headache disorder, which causes significant socioeconomic problems worldwide. The pathomechanism of disease is enigmatic, but activation of the trigeminovascular system (TS) appears to be essential during the attack. Migraine research of recent years has focused on neuropeptides, such as calcitonin generelated peptide (CGRP) and pituitary adenylate cyclase-activating polypeptide 1-38 (PACAP1-38) as potential pathogenic factors and possible therapeutic offensives. The goal of present study was to investigate the simultaneous expression of CGRP and precursor of PACAP1-38 (preproPACAP) in the central region of the TS in a time-dependent manner following TS activation in rats.
\end{abstract}

Methods: The right whisker pad of rats was injected with $50 \mu$ l Complete Freund's Adjuvant (CFA) or saline. A mechanical allodynia test was performed with von Frey filaments before and after treatment. Transcardial perfusion of the animals was initiated 24, 48, 72 and $120 \mathrm{~h}$ after injection, followed by the dissection of the nucleus trigeminus caudalis (TNC). After preparation, the samples were stored at $-80^{\circ} \mathrm{C}$ until further use. The relative optical density of CGRP and preproPACAP was analyzed by Western blot. One-way ANOVA and Kruskal-Wallis followed by Tukey post hoc test were used to evaluate the data. Regression analysis was applied to explore the correlation between neuropeptides expression and hyperalgesia.

Results: Orofacial CFA injection resulted in significant CGRP and preproPACAP release in the TNC 24, 48, 72 and $120 \mathrm{~h}$ after the treatment. The level of neuropeptides reached its maximum at $72 \mathrm{~h}$ after CFA injection, corresponding to the peak of facial allodynia. Negative, linear correlation was detected between the expression level of neuropeptides and value of mechanonociceptive threshold.

Conclusion: This is the first study which suggests that the expression of CGRP and preproPACAP simultaneously increases in the central region of activated TS and it influences the formation of mechanical hyperalgesia. Our results contribute to a better understanding of migraine pathogenesis and thereby to the development of more effective therapeutic approaches.

Keywords: Migraine, Trigeminovascular system, CFA, CGRP, preproPACAP

\footnotetext{
* Correspondence: tajti.janos@med.u-szeged.hu

'Department of Neurology, Faculty of Medicine, Albert Szent-Györgyi Clinical

Center University of Szeged, Semmelweis u. 6, Szeged H-6725, Hungary

Full list of author information is available at the end of the article
}

(c) The Author(s). 2019 Open Access This article is distributed under the terms of the Creative Commons Attribution 4.0 International License (http://creativecommons.org/licenses/by/4.0/), which permits unrestricted use, distribution, and reproduction in any medium, provided you give appropriate credit to the original author(s) and the source, provide a link to the Creative Commons license, and indicate if changes were made. 


\section{Background}

Recently, two peptides of key molecules have been highlighted for their involvement in the pathomechanism of primary headache disorders: calcitonin gene-related peptide (CGRP), as an "old warrior" and pituitary adenylate cyclase-activating polypeptide 1-38 (PACAP1-38), which is a newer, potential target for headache therapies. These peptides are very similar in features and functions: e.g. they are potent vasodilators, they are present in both the peripheral and central nervous system and they can function in the transmission of nociception and neurogenic inflammation. Subsequently, they have gained ground in the therapeutic developments in migraine. In 2004, the first CGRP receptor antagonists (gepants) effectively terminated migraine in humans, but nowadays several other anti-CGRP treatments are in clinical trials or are under development (anti-CGRP and anti-CGRP receptor monoclonal antibodies) for the prevention of migraine [1]. PACAP1-38 also has pivotal role in migraine, as indicated by several preclinical [2-4] and clinical [5-9] examinations, but there are fewer confirmed results targeted on the PACAP1-38 antibody therapies [10]. The analogous behaviour of these peptides presents the possibility that anti-PACAP1-38 treatments could provide a therapeutic advantage for migraineurs who do not respond the anti-CGRP therapies.

Thus it is interesting to investigate the simultaneous release of CGRP and precursor of PACAP1-38 (preproPACAP) in a migraine-related environment. In our case, the orofacial Complete Freund's Adjuvant (CFA) rat model was selected to determine these alterations. CFA has been used for animal modelling of autoimmune and inflammatory illnesses for nearly 50 years and it is an accepted model of orofacial inflammatory hyperalgesia [11-16].

The precise mode of action of CFA is not known, but it primarily triggers an inflammatory reaction through the activation of the cellular immune response [11]. The CFA-induced chemical stimulation of the orofacial area can activate the extra- and intracranial trigeminal primary afferents, which provide the sensory innervation of the face and oral cavity, as well as the vasculature-associated meningeal nociceptive afferents. The cell bodies of these peripheral fibres are located in the trigeminal ganglion (TRG), while the central projections of these neurons terminate in the trigeminal nucleus caudalis (TNC). Sensitisation of the peripheral fibres and the second order nociceptive neurons in the TNC can contribute to the phenomenon of facial allodynia developing in primary headache disorders [17]. Perception of pain can be connected to the thalamic third order neurons [18-22].

This commonly used peripheral inflammation model can integrate those mechanisms which are involved in migraine, because several primary headache diseases associated with inflammation of extracranial structures, such as the temporomandibular joint (TMJ) or the sinuses, can be evoked by similar mechanisms to those mentioned above [16, 23, 24]. Comorbidity was also observed between migraine and TMJ disorders [25], therefore orofacial inflammation induced by CFA might be suitable to generate hyperalgesia/allodynia on the face by the activation/sensitization of the trigeminovascular system (TS), namely to mimic the features of migraine [12].

In the course of our research we aimed to model allodynia-associated activated TS using CFA in rats. We used von Frey filaments to assess nociceptive sensitization and measure the temporal changes in facial mechano-nociceptive threshold after periods of $24,48,72$, and $120 \mathrm{~h}$ following CFA injection. In order to estimate the release of neuropeptides in the TNC in the assessed time periods following CFA injection, Western blot assay was used with specific preproPACAP and CGRP antibodies.

This the first study which evaluated the presence of preproPACAP and CGRP together in the TNC and correlated the behavioural changes following facial inflammation. These investigations might provide better insight into the background of trigeminal pain disorders.

\section{Materials and methods \\ Animals}

Thirty young adult (10-12 weeks old) male Sprague-Dawley rats were used for the experiments. The animals were bred and maintained under standard laboratory conditions with a 12-12-h light/dark cycle at $24 \pm 1{ }^{\circ} \mathrm{C}$ and approx. $50 \%$ relative humidity in the Laboratory Animal House of the Department of Neurology. The rats had free access to standard rat chow and water.

\section{Ethics}

All experimental procedures performed in this study complied fully with the guidelines of Act 1998/XXVIII of the Hungarian Parliament on Animal Experiments (243/1988) and with the recommendations of the International Association for the Study of Pain and European Communities Council (86/609/ECC). The studies were in harmony with the Ethical Codex of Animal Experiments and were approved by the Ethics Committee of the Faculty of Medicine, University of Szeged, XI./1102/2018.

\section{Drugs}

Complete Freund's Adjuvant (killed mycobacteria suspended in paraffin oil; $1 \mathrm{mg} / \mathrm{ml}$ ) was obtained from Sigma-Aldrich Corporation (St. Louis, MO, USA), and $50 \mu \mathrm{l}$ was administered per animal.

\section{Orofacial pain sensitivity tested with von Frey filaments}

In this experiment mechanical pain thresholds of the orofacial region were determined with von Frey filaments. Tests were performed before (0) and at 24, 48, 
72, $120 \mathrm{~h}$ after CFA/saline injection. Animals were lightly restrained using a soft cotton glove in order to allow an easier habituation, then a set of calibrated nylon monofilaments (SENSElab - AESTHESIOMETER, SOMEDIC Sales AB, Box 194, 24231 Hörby) was used with increasing strengths (0.39-8.3 g) to measure facial mechanosensitivity. Filaments were applied in ascending order, starting from the $3.3 \mathrm{~g}$ filament during control measurements and the $0.39 \mathrm{~g}$ filament after CFA treatment. The mechanonociceptive threshold was defined as the lowest force evoking at least two withdrawal responses (face stroking with the forepaw or head shaking) out of five stimulations [12].

\section{Experimental protocol}

In our experiment five animal groups were created: 1 control group and 4 groups with CFA treatment. The groups and treatments are presented in Table 1.

First, the rats were anesthetized with intraperitoneal $4 \%$ chloral hydrate solution $(10 \mathrm{ml} / \mathrm{kg}$ bw dose $)$ and the anesthesia was maintained throughout the experiment. Next, $50 \mu \mathrm{l}$ of CFA was injected into the right whisker pad. Control rats were injected with an equal volume of saline. The von Frey allodynia test was performed before and after treatment, as described above. Transcardial perfusion of the animals with $200 \mathrm{ml}$ phosphate-buffered saline (PBS) was initiated 24, 48, 72 and $120 \mathrm{~h}$ after injection. The medullary segment containing TNC (between rostral $1 \mathrm{~mm}$ and caudal $5 \mathrm{~mm}$ from the obex) was removed. After preparation, the samples were stored at $-80^{\circ} \mathrm{C}$ until further use. The relative optical density of CGRP and preproPACAP was analyzed by Western blot.

\section{Protein quantification by Western blot analysis}

The samples were sonicated in ice-cold buffer containing $50 \mathrm{mM}$ Tris- $\mathrm{HCl}, 150 \mathrm{mM} \mathrm{NaCl}, 0.1 \%$ Igepal. $0.1 \%$ cholic acid, $2 \mathrm{mg} / \mathrm{ml}$ leupeptin, $2 \mathrm{mM}$ phenylmethylsulphonyl fluoride, $1 \mathrm{mg} / \mathrm{ml}$ pepstatin, $2 \mathrm{mM}$ ethylenediaminetetraacetic acid (EDTA), and $0.1 \%$ sodium dodecyl sulfate (SDS). After homogenization, the samples were centrifuged at $12.000 \mathrm{rpm}$ for $10 \mathrm{~min}$ at $4{ }^{\circ} \mathrm{C}$, and supernatants were aliquoted and stored at $20^{\circ} \mathrm{C}$ until use. The protein concentration was determined by the BCA Protein Assay Kit using BSA as the standard. Prior to protein separation, each sample was mixed with the sample buffer, and denatured by boiling for $5 \mathrm{~min}$. Equal amounts of protein samples $(20$ $\mathrm{mg} / \mathrm{lane}$ ) were separated by standard SDS polyacrylamide gel electrophoresis on 10\% Tris-Glycine gel and electrotransferred onto an AmershamHybond-ECL nitrocellulose membrane $(0.45-\mathrm{mm}$ pore size). We used the Page Ruler Prestained Protein Ladder $(10-170 \mathrm{kDa})$ to define approximate molecular weights. Following blotting, the membranes were blocked for $1 \mathrm{~h}$ at room temperature in Tris-buffered saline containing Tween 20 (TBST) and 5\% nonfat dry milk powder. Subsequently, the membranes were incubated in TBST containing $1 \%$ nonfat dry milk and anti-PACAP antibody (against the $\mathrm{C}$ terminal; ab174982, dilution: 1:500, incubation parameters: overnight, $4{ }^{\circ} \mathrm{C}$ ) or anti-CGRP antibody (Sigma-Aldrich-c8198, dilution: 1:2000, incubation parameters: overnight, room temperature), anti-glyceraldehyde 3-phosphate dehydrogenase (GAPDH) antibody (D16H11, dilution: 1:1000, incubation parameters: overnight, room temperature). The following day, the membranes were incubated in TBST containing $1 \%$ nonfat dry milk powder and horseradish peroxidase-conjugated goat anti-rabbit secondary antibody (sc-2030, Santa Cruz Biotechnology) for $2 \mathrm{~h}$ at room temperature. The protein bands were revealed with Syngene PXi 6 Access Touch Gel Documentation System.

\section{Statistical analysis}

The Shapiro-Wilk test was used to determine the distribution of data. Data of the Western blot analysis followed a normal distribution, so after the One-way ANOVA test we used the Tukey's post hoc test to analyze the results. The data from the von Frey allodynia test did not show a normal distribution, therefore we used the Kruskal-Wallis test with Tukey's post hoc test. A probability level of $p<0.05$ was considered significant. Mean \pm SD are represented in the diagrams. Regression analyses were performed between the levels of neuropeptides and the value of hyperalgesia with SPSS 20.0 Software.

\section{Results \\ Orofacial CFA treatment resulted in significant preproPACAP increase in the TNC}

A significant increase in the relative optical density of preproPACAP was observed 24 (0.58), 48 (0.69), 72 (1.01) and $120(0.85)$ hours after CFA treatment compared to the control group (0.49). The highest preproPACAP concentration was measured $72 \mathrm{~h}$ after the CFA treatment. The difference between the $72 \mathrm{~h}$ and $120 \mathrm{~h}$ groups was significant, therefore we did not feel it necessary to include other group investigations (Figs. 1 and 2).

Table 1 Experimental groups

\begin{tabular}{|c|c|c|c|c|c|}
\hline Group & $\begin{array}{l}\text { Control } \\
(n=6)\end{array}$ & $\begin{array}{l}\text { CFA } 1 \\
(n=6)\end{array}$ & $\begin{array}{l}\text { CFA } 2 \\
(n=6)\end{array}$ & $\begin{array}{l}\text { CFA } 3 \\
(n=6)\end{array}$ & $\begin{array}{l}\text { CFA } 4 \\
(n=6)\end{array}$ \\
\hline Orofacial treatment & $50 \mu$ l saline & $50 \mu \mathrm{l} \mathrm{CFA}$ & $50 \mu \mathrm{l} C F A$ & $50 \mu \mathrm{lCFA}$ & $50 \mu \mathrm{l} \mathrm{CFA}$ \\
\hline Perfusion and dissection & $24 \mathrm{~h}$ after treatment & $24 \mathrm{~h}$ after treatment & $48 \mathrm{~h}$ after treatment & $72 \mathrm{~h}$ after treatment & $120 \mathrm{~h}$ after treatment \\
\hline
\end{tabular}




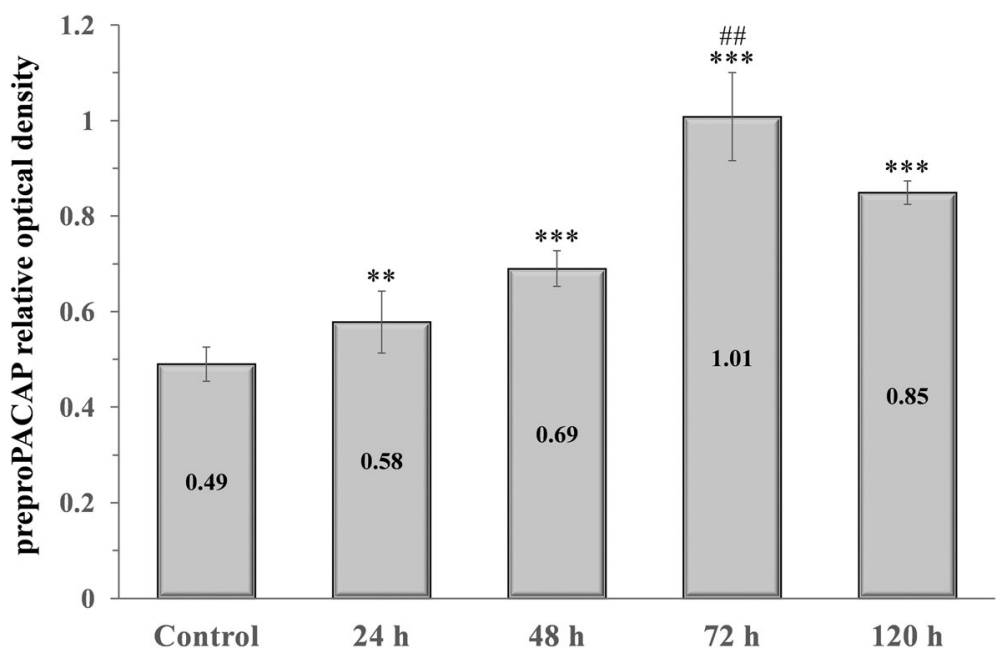

Fig. 1 Relative optical density of the preproPACAP protein in the TNC following orofacial CFA treatment. ${ }^{* *} p<0.001$ vs. Control group, ${ }^{* *} p<0.01$ vs. Control group, \#\# $p<0.01$ vs. 120 h group, Mean $\pm S D, n=6$

Orofacial CFA treatment significantly elevated CGRP relative optical density in the TNC

CGRP expression in the TNC was elevated 24 (0.99), 48 (1.26), 72 (2.36) and 120 (2.1) hours after CFA injection compared to the control group (0.73). The highest CGRP concentration was detected $72 \mathrm{~h}$ after CFA treatment. The difference was significant between the $72-\mathrm{h}$ and 120-h groups, therefore we did not feel it was necessary to include other group investigations (Figs. 3 and 4).

\section{Orofacial CFA injection decreased the mechanonociceptive threshold}

The facial mechanonociceptive threshold decreased significantly compared to the contralateral side 48, 72 and $120 \mathrm{~h}$ after CFA treatment. Compared to the control measurement (7.77), the threshold was reduced significantly 24 (6.64), 48 (4.1), 72 (2.1) and 120 (2.77) hours after CFA treatment. Allodynia reached its maximum at $72 \mathrm{~h}$, as the threshold change was lower by $120 \mathrm{~h}$. We did not find significant differences in the threshold of the contralateral whisker pad area (Fig. 5).

\section{Correlation between neuropeptides expression and mechanical hyperalgesia}

Reverse relationship was observed between the concentrations of neuropeptides and the value of the evoked mechanical threshold (CFA treated whisker pad) depending on the time. All data of the saline treated control group and the CFA treated groups were involved in the statistical probe. Regression analyses have revealed that negative, linear correlation is found between the expression levels of preproPACAP or CGRP and the levels of hyperalgesia. Then data were mixed with bootstrap analyses $(1000 \mathrm{x})$, which resulted in the following values: $n=30, \mathrm{p}_{\text {CGRP }}<0.001, \mathrm{R}_{\mathrm{CGRP}}=-0.846 ; n=30, \mathrm{p}_{\text {preproPA }}$ CAP $<0.001, R_{\text {preproPACAP }}=-0.792$ (Fig. 6).

\section{Discussion}

Migraine research in recent years has focused on neuropeptides as potential pathogenic factors and possible therapeutic alternatives. Neuropeptides such as hemokinin A, neurotensin, substance P (SP), CGRP and PACAP1-38 can activate mast cells, leading to the secretion of

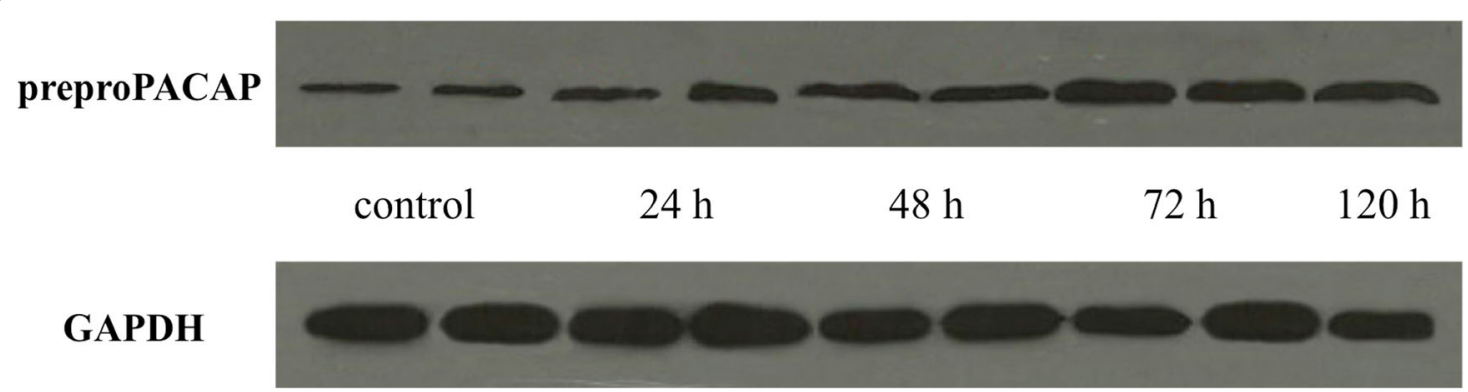

$19 \mathrm{kDa}$

Fig. 2 Western blot of preproPACAP and GAPDH expression in the TNC 


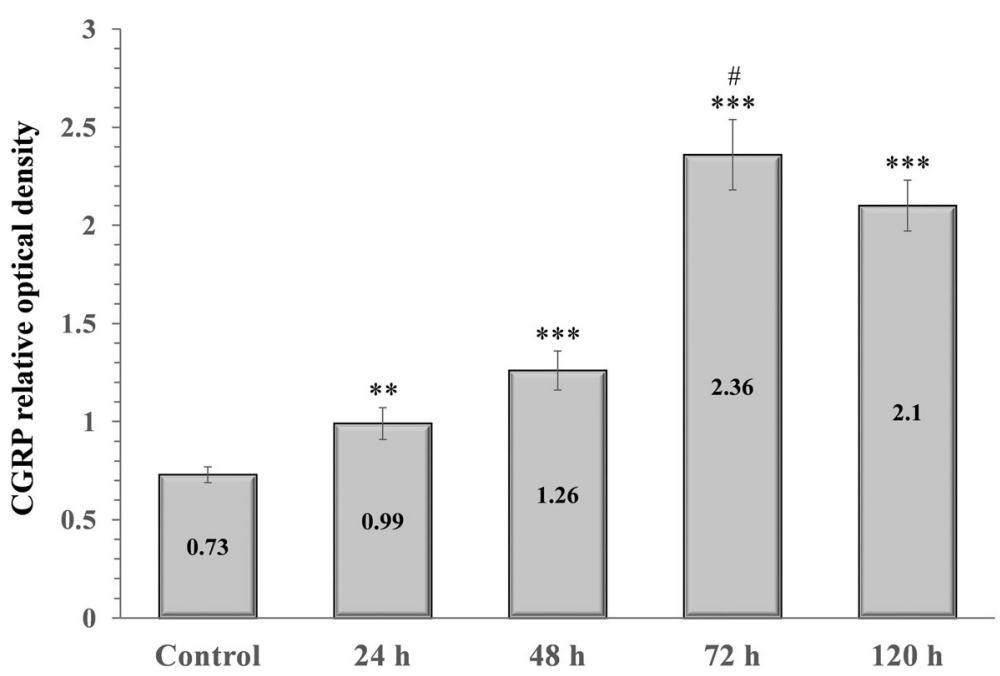

Fig. 3 Relative optical density of the CGRP protein in the TNC following orofacial CFA treatment. ${ }^{* *} p<0.001$ vs. Control group, ${ }^{* *} p<0.01$ vs. Control group, \# $p<0.05$ vs. $120 \mathrm{~h}$ group, Mean \pm SD, $n=6$

vasoactive, proinflammatory and neuro-sensitizing mediators, thereby contributing to the activation of TS [26, 27].

The aim of the present study was to investigate the simultaneous expression of CGRP and preproPACAP in the central region of the TS in a time-dependent manner following orofacial CFA treatment. Orofacial CFA injection evokes significant CGRP and preproPACAP increase in the TNC $24 \mathrm{~h}$ after treatment. The neuropeptide levels reach a maximum at $72 \mathrm{~h}$ after CFA injection, corresponding to the peak of facial allodynia.

Our opinion is that the CFA-induced inflammation can evoke continuous and long-term neuropeptide release in the TNC, which is accompanied by manifestation of mechanical hyperalgesia. It is assumed that the CFA can maintain this effect until $72 \mathrm{~h}$, then both the preproPACAP and CGRP level start to decrease in the absence of stimulus, which causes the relief of allodynia. Our presumption is supported by a recent study, where the repetitive electrical stimulation of dura mater induced elevation in the expression level of CGRP and
PACAP in the TRG and TNC in rat depending on the stimulation periods (1, 3 and 7 days). It suggests that the number of stimulations can influence the release and effects of neuropeptides [28]. Our results are consistent with a previous study, where the orofacial CFA injection provoked increased CGRP expression in the TNC, which elevation reached its maximum 3 days after CFA treatment [12]. In another study, activated microglial cells were detected in the ipsilateral TNC and in the cervical dorsal horn $72 \mathrm{~h}$ after orofacial CFA treatment of rats [29]. In this context, the activated microglial cells might also be involved to the mechanism of central sensitization and nociception [30-32]. It is proved that an antagonist of P2X4 microglia receptor blocked the NTG-induced c-Fos and CGRP release in the TNC, subsequently the hyperalgesia [33]. Results of our functional test showed that orofacial CFA injection can already cause a significant increase in mechanical allodynia $24 \mathrm{~h}$ after treatment. Allodynia reached its maximum on day 3 , as the threshold change was lower by day 5 . These

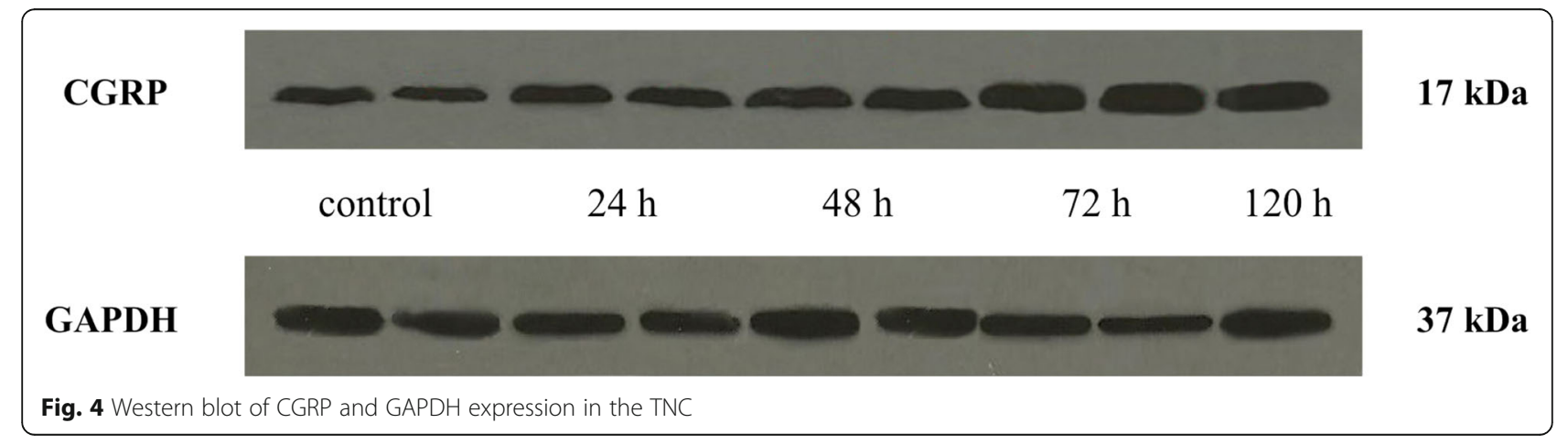




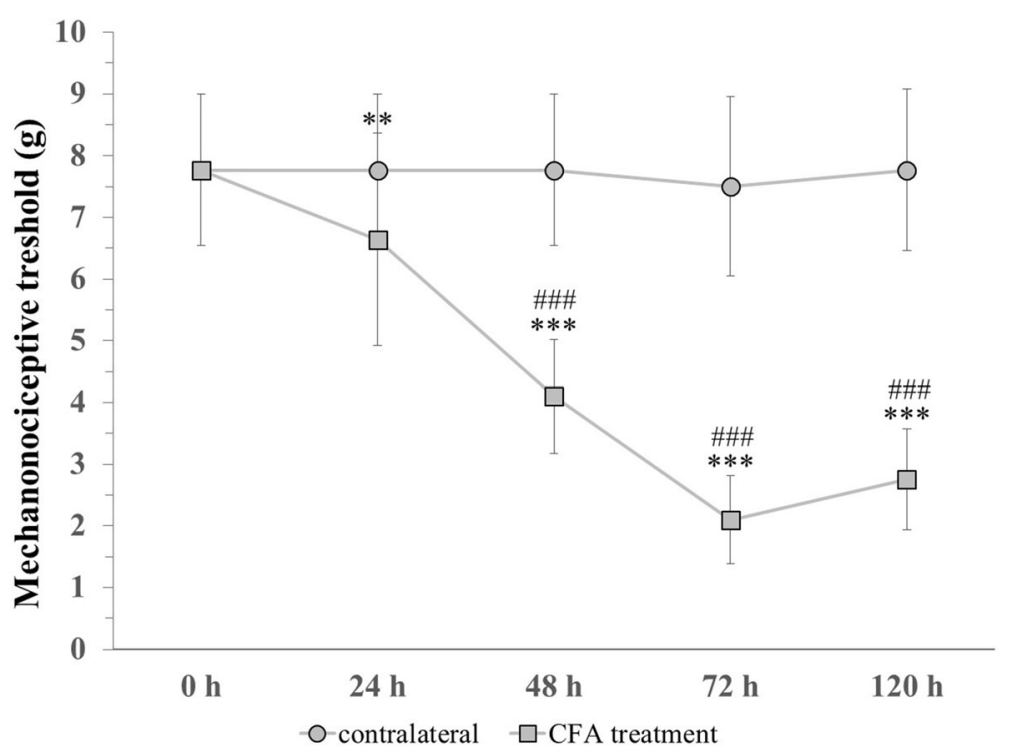

Fig. 5 Changes in mechanical theshold before (0) and 24, 48, 72, $120 \mathrm{~h}$ after CFA treatment. ${ }^{* * *} p<0.001$ vs. Control measurement (0 h) in CFA treatment group, ${ }^{* *} p<0.01$ vs. Control measurement ( 0 h) in CFA treatment group, \#\#\# $p<0.001$ vs. contralateral side. Mean $\pm S D, n=6-24$

results are consistent with observations from animal investigations where the CFA induced chronic pain-like behaviour 3 days after treatment [12, 14, 34]. Additionally, it was also demonstrated that chronic stimulation of dura mater can elicit facial cutaneous allodynia during the migraine chronification, via CGRP and PACAP elevation. One of the potential mechanisms, which can mediate the effect of PACAP is that its autoreceptor (PAC1) can influence the G-protein-coupled downstream effects via regulating the pre- and postsynaptic events [28]. Nevertheless, the moderating functional alterations might also be explained by the desensitization of receptors, but further investigations are needed to answer this hypothesis.
Another important result of present study is that the alterations of CGRP and preproPACAP expression show correlation with change of mechanical threshold. Several studies have proved to the key role of CGRP and PACAP1-38 mediators of neurogenic inflammation and modulators of pain inputs $[2,35,36]$. The release of these neuropeptides in the central nervous system facilitate nociceptive signalling and in the periphery contribute to vasodilatation of meningeal vessels and neurogenic inflammation [37]. Based on our results probable that the CFA-induced CGRP and PACAP1-38 increase play crucial role in triggering central sensitization, thereby regulation of these peptides may influence the rate of mechanical hyperalgesia [38].
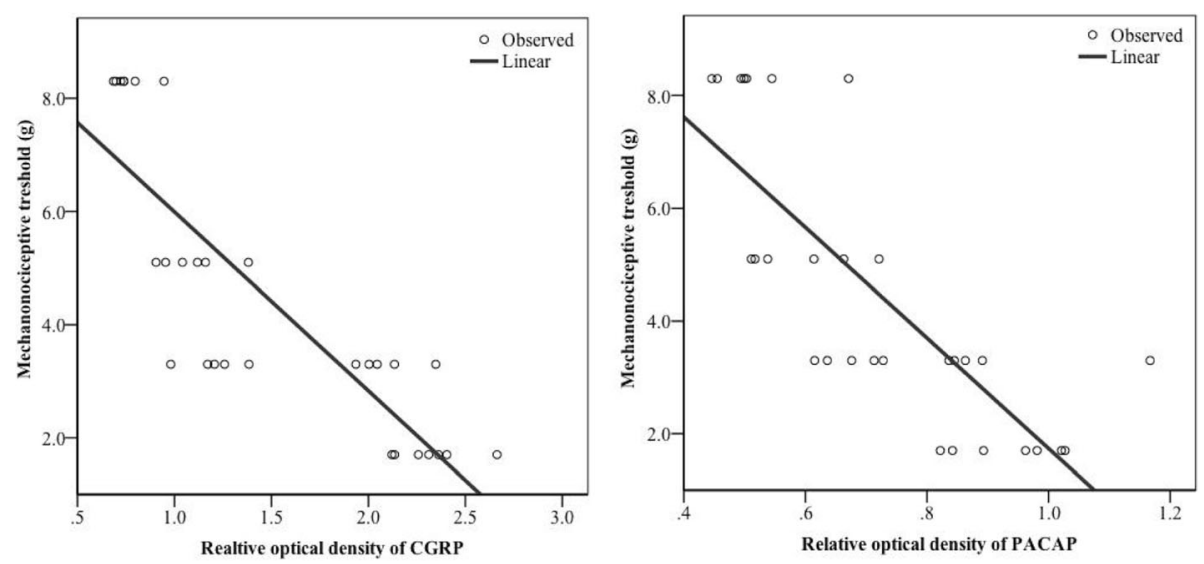

Fig. 6 Negative, linear correlation between expression levels of neuropeptides and mechanonociceptive threshold 
Role of neuropeptides in preclinical migraine models A classical study confirmed that the concentration of CGRP and SP were increased during electrical stimulation of TRG (ES-TRG) of the external jugular vein of cats [39]. A former study suggests that ES-TRG resulted in significantly elevated PACAP1-38 immunoreactivity $180 \mathrm{~min}$ after ES-TRG of the plasma and PACAP1-38 and PACAP1-27 immunoreactivity in the TNC. Besides ES-TRG, the intraperitoneal administration of nitroglycerin (NTG) also induced an increase in PACAP1-38 and PACAP1-27 expression $3 \mathrm{~h}$ after the treatment in the TNC [3]. A study showed that PACAP1-38 administration can result in increased CGRP expression in the TNC, which points to a potential connection between release of CGRP and PACAP1-38 [40]. Co-expression of CGRP and PACAP138 was investigated: $23 \%$ of the neurons expressed both CGRP and PACAP1-38 in rat TRG, and CGRP (49\%) was expressed in more neuronal somas compared to PACAP138 (29\%) [41]. In a preclinical model of migraine, the simultaneous release of CGRP and PACAP was detected: a chronic NTG treatment caused increased concentrations of these peptides in the plasma of rats, furthermore the intervention evoked mechanical and thermal hyperalgesia [38].

Nevertheless the activation of TS could be formed by different CFA treatments, which results pain associated pathological states, including migraine, neuralgias and TMJ disorders [25]. In our previous study, we investigated the effect of CFA on the expression of mitogen-activated protein kinases (MAPK), which play essential roles in pain processing. Administration of CFA in the TMJ caused significant extracellular signal-regulated kinase $1 / 2($ ERK1/2) and p38 MAPK increase in the TRG [42]. Dural administration of CFA resulted elevated ERK1/2, interleukin-1 $\beta$ and CGRP expression in the TRG [11], as well as increased c-fos and glutamate immunoreactivity in the TNC and cervical neurons [43]. Moreover, gene expression alterations (CGRP, Iba1, GFAP, etc.) were detected following orofacial CFA treatment in the TRG and TNC [12], which suggest that the CFA induced neuroinflammation can evoke increased CGRP and PACAP1-38 levels.

\section{Role of neuropeptides in clinical studies}

In migraineurs, the level of CGRP in the peripheral blood increases during a migraine attack as compared to the attack free $[8,39,44,45]$. A very similar observation has recently been made for PACAP1-38 as well, suggesting a potential biomarker function of PACAP1-38 in the disease [8]. In addition, similarly to CGRP [35], intravenous administration of PACAP1-38 induced headache and vasodilatation, both in healthy subjects and patients suffering from migraine, whereas it delayed migraine-like attacks only in migraineurs $[46,47]$. Magnetic resonance imaging angiography examinations proved that PACAP1-38 induced headache is associated with prolonged vasodilatation of the middle meningeal artery (MMA), but not the middle cerebral artery (MCA). Sumatriptan was able to alleviate the headache, which mirrored the contraction of the MMA, but not the MCA, suggesting that PACAP1-38-induced headaches may arise from the extracerebral arteries [48]. Correlation was showed between the interictal plasma PACAP1-38 immunoreactivity and the microstructural integrity of the white matter in migraineurs [5]. These data support the idea that neuropeptides could be a good candidate for the new therapeutic approaches.

Nowadays the therapies based on monoclonal antibodies of CGRP seem to be promising in the prevention of migraine [49]. Recently, a phase 3 clinical trial showed that 12 months of treatment with galcanezumab, which is a fully humanized CGRP monoclonal antibody, was safe and associated with a reduction in the number of monthly migraine headache days [50]. Besides galcanezumab, erenumab, eptinezumab and fremanezumab were able to reduce the frequency of attacks in patients with episodic migraine [51].

Considering the similar behaviours of CGRP and PACAP1-38, the therapies aimed at PACAP1-38 may also be useful for those who have an inadequate response to therapeutics directed at CGRP or its receptors. A phase 2a, randomized, double blind, placebo-controlled study is underway to appraise the efficacy and safety of a PAC1 receptor antibody (AMG 301) in subjects with chronic or episodic migraine (Study to Evaluate the Efficacy and Safety of AMG 301 in Migraine Prevention. https://clinicaltrials.gov/ct2/show/NCT03238781. Accessed 02 May 2018). Preclinical studies are also evaluating a monoclonal antibody (ALD1910) targeting PACAP1-38 (ALD1910 migraine prevention. alderbio.com. https://www.alderbio. com/pipeline/ald1910/. Accessed 19 May 2018, [10]. Monoclonal antibodies may be crucial in the therapy of migraine however it needs further examinations to certify their relevance.

\section{Conclusion}

Our results provided the first direct evidence that the expression levels of CGRP and preproPACAP simultaneously increase after CFA induced trigeminal activation in the central region of the TS. Correlations, which were found between the alterations of CGRP/preproPACAP expression and mechanical threshold prove the influence of neuropeptides in the mechanism of hyperalgesia. Data of the present study contribute to the better understanding of migraine pathogenesis and support the idea that neuropeptides may have therapeutic value in migraine treatment.

Abbreviations

BSA: Bovine serum albumin; CFA: Complete Freund's adjuvant; CGRP: Calcitonin gene-related peptide; EDTA: Ethylenediaminetetraacetic acid; ERK1/2:

Extracellular signal-regulated kinase 1/2; ES-TRG: Electrical stimulation of the 
TRG; MAPK: Mitogen-activated protein kinase; MCA: Middle cerebral artery; MMA: Middle meningeal artery; NTG: Nitroglycerin; PACAP: Pituitary adenylate cyclase-activating polypeptide; PACAP1-27: 27 amino acid form of PACAP; PACAP1-38: 38 amino acid form of PACAP; PBS: Phosphate-buffered saline; SDS: Sodium dodecyl sulfate; SP: Substance P; TBST: Tris-buffered saline containing Tween 20; TMJ: Temporomandibular joint; TNC: Trigeminal nucleus caudalis; TRG: Trigeminal ganglion; TS: Trigeminovascular system; VIP: Vasoactive intestinal polypeptide

\section{Acknowledgments}

We are grateful to Jennifer Tusz for her valuable contribution in proofreading the manuscript.

\section{Funding}

This work was supported by the project GINOP-2.3.2-15-2016-00034, the Ministry of Human Capacities, Hungary grant 20391-3/2018/FEKUSTRAT and MTA-SZTE Neuroscience Research Group.

\section{Availability of data and materials}

The datasets used and/or analysed during the current study are available from the corresponding author on reasonable request.

\section{Authors' contributions}

TK: participated in the design and implementation of experiments, statistical analysis, data interpretation and he wrote the manuscript, BT: participated in the implementation of the experiments and she wrote the manuscript ANY: participated in the implementation of experiments and she wrote the manuscript $\mathrm{LV}$ : participated in the conception and design of the experiments, the interpretation of the data and writing, all authors: critical revision of the manuscript. JT: participated in the design of the experiments and in the final approval of the version to be published.

\section{Ethics approval and consent to participate}

Not applicable.

\section{Consent for publication}

Not applicable.

\section{Competing interests}

The authors declare that they have no competing interests.

\section{Publisher's Note}

Springer Nature remains neutral with regard to jurisdictional claims in published maps and institutional affiliations.

\section{Author details}

'Department of Neurology, Faculty of Medicine, Albert Szent-Györgyi Clinical Center University of Szeged, Semmelweis u. 6, Szeged H-6725, Hungary. ${ }^{2}$ MTA-SZTE Neuroscience Research Group, University of Szeged, Semmelweis u. 6, Szeged H 6725, Hungary. ${ }^{3}$ Department of Neurology, Interdisciplinary Excellence Centre, Faculty of Medicine, Albert Szent-Györgyi Clinical Center, University of Szeged, Semmelweis u. 6, Szeged H-6725, Hungary.

\section{Received: 13 February 2019 Accepted: 16 April 2019}

\section{Published online: 29 April 2019}

\section{References}

1. Tepper SJ (2018) Anti-calcitonin gene-related peptide (CGRP) therapies: update on a previous review after the American headache society 60th scientific meeting, San Francisco, June 2018. Headache 58(Suppl 3):276-290

2. Markovics A, Kormos V, Gaszner B, Lashgarara A, Szoke E, Sandor K et al (2012) Pituitary adenylate cyclase-activating polypeptide plays a key role in nitroglycerol-induced trigeminovascular activation in mice. Neurobiol Dis 45(1):633-644

3. Tuka B, Helyes Z, Markovics A, Bagoly T, Nemeth J, Mark L et al (2012) Peripheral and central alterations of pituitary adenylate cyclase activating polypeptide-like immunoreactivity in the rat in response to activation of the trigeminovascular system. Peptides 33(2):307-316

4. Syed AU, Koide M, Braas KM, May V, Wellman GC (2012) Pituitary adenylate cyclase-activating polypeptide (PACAP) potently dilates middle meningeal arteries: implications for migraine. J Mol Neurosci 48(3):574-583
5. Vereb D, Szabo N, Tuka B, Tajti J, Kiraly A, Farago P et al (2018) Correlation of neurochemical and imaging markers in migraine: PACAP38 and DTI measures. Neurology 91(12):e1166-e1e74

6. Han X, Ran Y, Su M, Liu Y, Tang W, Dong Z et al (2017) Chronic changes in pituitary adenylate cyclase-activating polypeptide and related receptors in response to repeated chemical dural stimulation in rats. Mol Pain 13: 1744806917720361

7. Hansen JM, Fahrenkrug J, Petersen J, Wienecke T, Olsen KS, Ashina M (2013) Vasoactive intestinal peptide (VIP) and pituitary adenylate cyclase-activating polypeptide (PACAP) in the circulation after sumatriptan. Scand J Pain 4(4): 211-216

8. Tuka B, Helyes Z, Markovics A, Bagoly T, Szolcsanyi J, Szabo N et al (2013) Alterations in PACAP-38-like immunoreactivity in the plasma during ictal and interictal periods of migraine patients. Cephalalgia 33(13):1085-1095

9. Hou L, Wan D, Dong Z, Tang W, Han X, Li L et al (2016) Pituitary adenylate cyclase-activating polypeptide expression in peripheral blood mononuclear cells of migraineurs. Cell Biosci 6:40

10. Rubio-Beltran E, Correnti E, Deen M, Kamm K, Kelderman T, Papetti L et al (2018) PACAP38 and PAC1 receptor blockade: a new target for headache? J Headache Pain 19(1):64

11. Lukacs M, Haanes KA, Majlath Z, Tajti J, Vecsei L, Warfvinge K et al (2015) Dural administration of inflammatory soup or complete Freund's adjuvant induces activation and inflammatory response in the rat trigeminal ganglion. J Headache Pain 16:564

12. Aczel T, Kun J, Szoke E, Rauch T, Junttila S, Gyenesei A et al (2018) Transcriptional alterations in the trigeminal ganglia, Nucleus and Peripheral Blood Mononuclear Cells in a Rat Orofacial Pain Model. Front Mol Neurosci 11:219

13. Morgan JR, Gebhart GF (2008) Characterization of a model of chronic orofacial hyperalgesia in the rat: contribution of $N A(V)$ 1.8. J Pain 9(6): 522-531

14. Okumura M, Iwata K, Yasuda K, Inoue K, Shinoda M, Honda K et al (2010) Alternation of gene expression in trigeminal ganglion neurons following complete Freund's adjuvant or capsaicin injection into the rat face. J Mol Neurosci 42(2):200-209

15. Ren K, Dubner R (1999) Inflammatory models of pain and hyperalgesia. ILAR 40(3):111-118

16. Krzyzanowska A, Avendano C (2012) Behavioral testing in rodent models of orofacial neuropathic and inflammatory pain. Brain Behav 2(5):678-697

17. Malick A, Burstein R (2000) Peripheral and central sensitization during migraine. Funct Neurol 15(Suppl 3):28-35

18. Kolhekar R, Murphy S, Gebhart GF (1997) Thalamic NMDA receptors modulate inflammation-produced hyperalgesia in the rat. Pain 71(1):31-40

19. Ab Aziz CB, Ahmad AH (2006) The role of the thalamus in modulating pain. Malays J Med Sci 13(2):11-18

20. Buzzi MG, Moskowitz MA (1992) The trigemino-vascular system and migraine. Pathologie-biologie 40(4):313-317

21. Noseda R, Burstein R. Migraine pathophysiology: anatomy of the trigeminovascular pathway and associated neurological symptoms, CSD, sensitization and modulation of pain. Pain. 2013;154(Suppl 1). PMID: 24347803.

22. Pietrobon D, Moskowitz MA (2013) Pathophysiology of migraine. Annu Rev Physiol 75:365-391

23. Krzyzanowska A, Pittolo S, Cabrerizo M, Sanchez-Lopez J, Krishnasamy S, Venero C et al (2011) Assessing nociceptive sensitivity in mouse models of inflammatory and neuropathic trigeminal pain. J Neurosci Methods 201(1):46-54

24. Romero-Reyes M, Akerman S, Nguyen E, Vijjeswarapu A, Hom B, Dong HW et al (2013) Spontaneous behavioral responses in the orofacial region: a model of trigeminal pain in mouse. Headache 53(1):137-151

25. Romero-Reyes M, Uyanik JM (2014) Orofacial pain management: current perspectives. J Pain Res 7:99-115

26. Tajti J, Szok D, Majlath Z, Tuka B, Csati A, Vecsei L (2015) Migraine and neuropeptides. Neuropeptides 52:19-30

27. Romero-Reyes M, Pardi V Akerman S (2015) A potent and selective calcitonin gene-related peptide (CGRP) receptor antagonist, MK-8825, inhibits responses to nociceptive trigeminal activation: role of CGRP in orofacial pain. Exp Neurol 271:95-103

28. Zhang Q, Han X, Wu H, Zhang M, Hu G, Dong Z et al (2019) Dynamic changes in CGRP, PACAP, and PACAP receptors in the trigeminovascular system of a novel repetitive electrical stimulation rat model: relevant to migraine. Mol Pain 15: 1744806918820452 
29. Villa G, Ceruti S, Zanardelli M, Magni G, Jasmin L, Ohara PT et al (2010) Temporomandibular joint inflammation activates glial and immune cells in both the trigeminal ganglia and in the spinal trigeminal nucleus. Mol Pain 6:89

30. Biggs JE, Lu VB, Stebbing MJ, Balasubramanyan S, Smith PA (2010) Is BDNF sufficient for information transfer between microglia and dorsal horn neurons during the onset of central sensitization? Mol Pain 6:44

31. Liu C, Zhang Y, Liu Q, Jiang L, Li M, Wang S et al (2018) P2X4-receptor participates in EAAT3 regulation via BDNF-TrkB signaling in a model of trigeminal allodynia. Mol Pain 14:1744806918795930

32. Anand P, Shenoy R, Palmer JE, Baines AJ, Lai RY, Robertson J et al (2011) Clinical trial of the p38 MAP kinase inhibitor dilmapimod in neuropathic pain following nerve injury. Eur J Pain 15(10):1040-1048

33. Long T, He W, Pan Q, Zhang S, Zhang Y, Liu C et al (2018) Microglia P2X4 receptor contributes to central sensitization following recurrent nitroglycerin stimulation. J Neuroinflammation 15(1):245

34. Liverman CS, Brown JW, Sandhir R, Klein RM, McCarson K, Berman NE (2009) Oestrogen increases nociception through ERK activation in the trigeminal ganglion: evidence for a peripheral mechanism of allodynia. Cephalalgia 29(5):520-531

35. Lassen $L H$, Haderslev PA, Jacobsen VB, Iversen HK, Sperling B, Olesen J (2002) CGRP may play a causative role in migraine. Cephalalgia 22(1):54-61

36. Ramon C, Cernuda-Morollon E, Pascual J (2017) Calcitonin gene-related peptide in peripheral blood as a biomarker for migraine. Curr Opin Neurol 30(3):281-286

37. Messlinger K, Fischer MJ, Lennerz JK (2011) Neuropeptide effects in the trigeminal system: pathophysiology and clinical relevance in migraine. Keio J Med 60(3):82-89

38. Mahmoudi J, Mohaddes G, Erfani M, Sadigh-Eteghad S, Karimi P, Rajabi M et al (2018) Cerebrolysin attenuates hyperalgesia, photophobia, and neuroinflammation in a nitroglycerin-induced migraine model in rats. Brain Res Bull 140:197-204

39. Goadsby PJ, Edvinsson L, Ekman R (1988) Release of vasoactive peptides in the extracerebral circulation of humans and the cat during activation of the trigeminovascular system. Ann Neurol 23(2):193-196

40. Jansen-Olesen I, Baun M, Amrutkar DV, Ramachandran R, Christophersen DV, Olesen J (2014) PACAP-38 but not VIP induces release of CGRP from trigeminal nucleus caudalis via a receptor distinct from the PAC1 receptor. Neuropeptides 48(2):53-64

41. Eftekhari S, Salvatore CA, Johansson S, Chen TB, Zeng Z, Edvinsson L (2015) Localization of CGRP, CGRP receptor, PACAP and glutamate in trigeminal ganglion. Relation to the blood-brain barrier. Brain Res 1600:93-109

42. Csati A, Edvinsson L, Vecsei L, Toldi J, Fulop F, Tajti J et al (2015) Kynurenic acid modulates experimentally induced inflammation in the trigeminal ganglion. J Headache Pain 16:99

43. Lukacs M, Warfvinge K, Tajti J, Fulop F, Toldi J, Vecsei L et al (2017) Topical dura mater application of CFA induces enhanced expression of c-fos and glutamate in rat trigeminal nucleus caudalis: attenuated by KYNA derivate (SZR72). J Headache Pain 18(1):39

44. Cernuda-Morollon E, Larrosa D, Ramon C, Vega J, Martinez-Camblor P, Pascual J (2013) Interictal increase of CGRP levels in peripheral blood as a biomarker for chronic migraine. Neurology 81(14):1191-1196

45. Goadsby PJ, Edvinsson L (1993) The trigeminovascular system and migraine: studies characterizing cerebrovascular and neuropeptide changes seen in humans and cats. Ann Neurol 33(1):48-56

46. Schytz HW, Birk S, Wienecke T, Kruuse C, Olesen J, Ashina M (2009) PACAP38 induces migraine-like attacks in patients with migraine without aura. Brain 132(Pt 1):16-25

47. Guo S, Vollesen AL, Hansen RD, Esserlind AL, Amin FM, Christensen AF et al (2017) Part I: pituitary adenylate cyclase-activating polypeptide-38 induced migraine-like attacks in patients with and without familial aggregation of migraine. Cephalalgia 37(2):125-135

48. Amin FM, Asghar MS, Guo S, Hougaard A, Hansen AE, Schytz HW et al (2012) Headache and prolonged dilatation of the middle meningeal artery by PACAP38 in healthy volunteers. Cephalalgia 32(2):140-149

49. Levin M, Silberstein SD, Gilbert R, Lucas S, Munsie L, Garrelts A et al (2018 Basic considerations for the use of monoclonal antibodies in migraine. Headache 58(10):1689-1696

50. Camporeale A, Kudrow D, Sides R, Wang S, Van Dycke A, Selzler KJ et al (2018) A phase 3, long-term, open-label safety study of Galcanezumab in patients with migraine. BMC Neurol 18(1):188

51. Edvinsson L (2018) Headache advances in 2017: a new horizon in migraine therapy. Lancet Neurol 17(1):5-6

Ready to submit your research? Choose BMC and benefit from:

- fast, convenient online submission

- thorough peer review by experienced researchers in your field

- rapid publication on acceptance

- support for research data, including large and complex data types

- gold Open Access which fosters wider collaboration and increased citations

- maximum visibility for your research: over $100 \mathrm{M}$ website views per year

At BMC, research is always in progress.

Learn more biomedcentral.com/submissions 